\title{
Abdominal hysterectomy for benign indications: evidence-based guidance for surgical decisions
}

\author{
Danish S. Siddiqui • Hussain Ali • Kiley A. Bernhard • \\ Vincenzo Berghella $\cdot$ Suneet P. Chauhan
}

Received: 11 June 2012 / Accepted: 28 July 2012 /Published online: 15 August 2012

(C) Springer-Verlag 2012

\begin{abstract}
The purpose of this review is to provide evidence-based guidance for surgical decisions during abdominal hysterectomy performed for benign indications. Using combinations of terms "abdominal," "hysterectomy," and "randomized clinical trials (RCT)," we performed Ovid, PubMed, and Cochrane searches for publications between 1988 and 2008. After reviewing over 3,000 abstracts, 19 RCT were identified. There are no grade A recommendations. The only grade B suggestion is use of a bipolar vessel sealing device (LigaSure) for vascular pedicles rather than sutures. Routine closure of peritoneum should be avoided. Evidence behind $71 \%(15 / 21)$ of surgical steps is insufficient (grade I). Despite its common performance, there are no grade A recommendations that can be made for the technical aspects of abdominal hysterectomy. Since almost $70 \%$ of the surgical steps during abdominal hysterectomy
\end{abstract}

This study was presented as an oral presentation at the "CAOG Annual Meeting, Maui, Hawaii, October 25-28, 2009."

D. S. Siddiqui $(\bowtie)$

Department of Obstetrics and Gynecology, School of Medicine and Public Health, University of Wisconsin,

945 N 12th Street-1K,

Milwaukee, WI 53233, USA

e-mail: danish.siddiqui@aurora.org

H. Ali

St. John's Hospital,

Lebanon, MO, USA

K. A. Bernhard

Aurora Health Care,

Milwaukee, WI, USA

V. Berghella

Jefferson Medical College, Thomas Jefferson University,

Philadelphia, PA, USA

S. P. Chauhan

Eastern Virginia Medical School,

Norfolk, VA, USA lack randomized clinical trials, adequately designed studies are needed to decrease perioperative morbidity.

Keywords Abdominal hysterectomy · Benign indication . Randomized controlled trials $\cdot$ Evidence-based medicine

\section{Background}

Hysterectomy, or removal of the uterus, is the most common major gynecologic procedure in the USA. Approximately, 600,000 hysterectomies were performed in the USA in the early 2000s [1] and 20 million US women have had their uterus removed [2]. From 1994-1999, the overall hysterectomy rate for US female was 5.5 per 1,000 women who are at least 15 years old [2]. Though the uterus can be removed vaginally, or with laparoscopy, the most common route is with open abdominal hysterectomy (AH). In 2003, there were 538,722 hysterectomies for benign disease, and about two thirds $(66 \%)$ of them were performed by abdominal laparotomy [3].

While the mortality with $\mathrm{AH}$ for benign indications is 0.25 per 1,000 procedures, morbidity occurs in $3-5 \%$. The potential complications include infection, blood transfusion, ureteral, bladder or intestinal injury, deep venous thrombosis, and pulmonary embolism [4-6]. One possible way to decrease the surgical complication rate is to ascertain what aspects of the surgery are evidence-based and have been linked with lower morbidity. Additionally, a review of the literature would identify the surgical decisions that are not based on randomized clinical trials (RCT) and potentially encourage properly designed trials.

The purpose of the review article is to provide gynecologists with evidence-based guidance during planned $\mathrm{AH}$ regarding operative technique and to identify the steps that need a properly conducted RCT. 


\section{Material and methods}

Since this is a literature search, an approval from the Institutional Review Board was not obtained. From TeLinde's Operative Gynecology, tenth edition [7], a standard textbook for gynecological surgeons, we identified 21 surgical steps for abdominal hysterectomy and sought RCTs for each one. Using combinations of terms "abdominal," "hysterectomy," "randomized clinical trials (RCT)," and each surgical aspect (e.g., minilaparotomy, open vaginal cuff), we performed Ovid, Cochrane, and PubMed searches for articles published between 1988 and 2008. Each publication and Cochrane review was examined, and the pertinent references were obtained. Articles were excluded if they were in foreign language, focused on antibiotics, pain management, cancer, cost-or-decision analysis, laparoscopy, vaginal hysterectomy, or did not discuss technical aspects of abdominal hysterectomy. Additionally, we excluded studies done on cadavers.

All RCTs that focused on a surgical aspect of abdominal hysterectomy were included. If there were no RCTs, nonrandomized reports with comparison groups were included in our analysis. Each step of the surgery was reviewed separately, and the evidence levels and recommendations were categorized according to the US Preventive Services Task Force (Tables 1 and 2) [8].

We excluded randomized trials that concurrently compared several steps of surgery because, with such a design, it is not feasible to directly compare the effects of each individual step [9]. We did not specifically review preoperative consideration like prophylactic oophorectomy and perioperative aspects such as prophylactic antibiotics and prevention of venous thromboembolic events for there are ACOG guidelines to inform clinicians [10-12]. Chi-square test for trend was done, and $P<0.05$ was considered significant.

\section{Findings}

Our literature search yielded 3,509 abstracts and of these, 3,392 (97\%) were excluded. The two most common reasons for excluding the articles were that the focus of the study was not a surgical aspect of hysterectomy or that it involved patients with cancer. We reviewed 117 articles that met the inclusion criteria (Fig. 1).

Patient position for AH is usually dorsal supine; however, some surgeons prefer lithotomy position so that a second assistant can be placed between the legs [7]. Patient position has not been studied separately in any trial (recommendation I; level of certainty, low).

Skin cleansing is done for the purpose to minimize wound complications and infectious morbidity. This can be performed using a variety of solutions (e.g., povidoneiodine, chlorhexidine gluconate, hexachlorophene). We did not identify any RCT evaluating the efficacy of any of these skin preparations in reducing the infectious wound morbidity (recommendation I; level of certainty, low).

Vaginal preparation involving preoperative cleansing has been advocated to reduce postoperative infectious morbidity. A variety of preparations are available (e.g., povidone-
Table 1 Recommendations according to US Preventive Services Task Force (USPSTF)

\begin{tabular}{|c|c|c|}
\hline Grade & Definition & Suggestions for practice \\
\hline A & $\begin{array}{l}\text { The USPSTF recommends the service. There is } \\
\text { high certainty that the net benefit is } \\
\text { substantial. }\end{array}$ & Offer or provide this service \\
\hline $\mathrm{B}$ & $\begin{array}{l}\text { The USPSTF recommends the service. There is } \\
\text { high certainty that the net benefit is moderate } \\
\text { or there is moderate certainty that the net } \\
\text { benefit is moderate to substantial. }\end{array}$ & Offer or provide this service \\
\hline $\mathrm{C}$ & $\begin{array}{l}\text { The USPSTF recommends against routine } \\
\text { providing of this service. There may be } \\
\text { considerations that support providing the } \\
\text { service in an individual patient. There is at } \\
\text { least moderate certainty that the net benefit is } \\
\text { small. }\end{array}$ & $\begin{array}{l}\text { Offer or provide this service only if other } \\
\text { considerations support the offering or } \\
\text { providing the service in an individual patient. }\end{array}$ \\
\hline $\mathrm{D}$ & $\begin{array}{l}\text { The USPSTF recommends against the service. } \\
\text { There is moderate or high certainty that the } \\
\text { service has no net benefit or that the harms } \\
\text { outweigh the benefits. }\end{array}$ & Discourage the use of this service. \\
\hline I & $\begin{array}{l}\text { The USPSTF concludes that the current } \\
\text { evidence is insufficient to assess the balance } \\
\text { of benefits and harms of the service. Evidence } \\
\text { is lacking, of poor quality, or conflicting, and } \\
\text { the balance of benefits and harms cannot be } \\
\text { determined. }\end{array}$ & $\begin{array}{l}\text { If the service is offered, patients should } \\
\text { understand the uncertainty about the balance } \\
\text { of benefits and harms. }\end{array}$ \\
\hline
\end{tabular}


Table 2 Level of certainty regarding the net benefit

\begin{tabular}{|c|c|}
\hline $\begin{array}{l}\text { Level of } \\
\text { certainty }\end{array}$ & Description \\
\hline High & $\begin{array}{l}\text { The available evidence usually includes consistent results from well-designed, well- } \\
\text { conducted studies in representative primary care populations. These studies assess the } \\
\text { effects on the preventive service on health outcomes. This conclusion is therefore } \\
\text { unlikely to be strongly affected by the results of future studies. }\end{array}$ \\
\hline Moderate & $\begin{array}{l}\text { The available evidence is sufficient to determine the effect of the preventive service on } \\
\text { health outcomes, but confidence in the estimate is constrained by such factors as: } \\
\text { - The number, size or quality of individual studies. } \\
\text { - Inconsistency of findings across individual studies } \\
\text { - Limited generalizability of findings to routine primary care practice } \\
\text { - Lack of coherence in the chain of evidence } \\
\text { As more information becomes available, the magnitude or direction of the observed effect } \\
\text { could change, and this change may be large enough to alter the conclusion }\end{array}$ \\
\hline Low & $\begin{array}{l}\text { The available evidence is insufficient to assess effect on health outcome. Evidence is } \\
\text { insufficient because of: } \\
\text { - The number or size of studies } \\
\text { - Important flaws in study design or methods } \\
\text { - Inconsistency of findings across individual studies } \\
\text { - Gaps in the chain of evidence } \\
\text { - Finding not generalizable to routine primary care practice } \\
\text { - Lack of information on important health outcomes } \\
\text { More information may allow estimation of effects on health outcomes. }\end{array}$ \\
\hline
\end{tabular}

iodine solution or gel, chlorhexidine). Three randomized trials, involving 1,889 patients, studied the preoperative vaginal cleansing using either povidone-iodine solution or gel. While two RCT $[13,14]$ did not show a decrease in infectious morbidity, Buppasiri et al. [15] noted a significant decrease with febrile morbidity. Specifically, they noted that the relative risk of infectious morbidity was 8 vs. $19 \%$, with

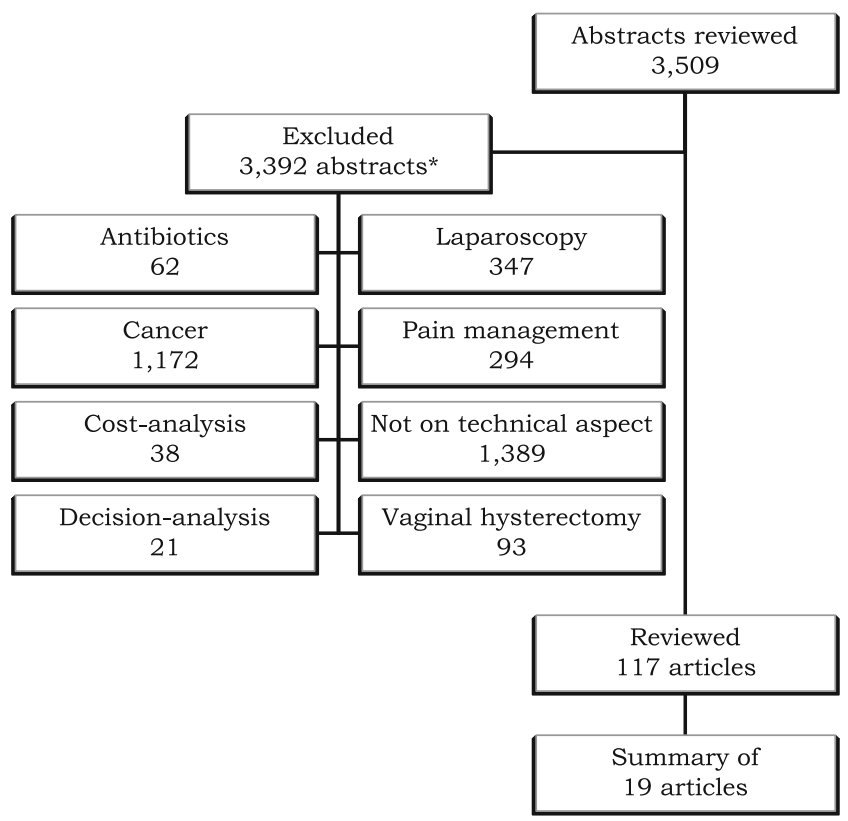

Fig. 1 Results of the literature search a risk difference of -10 , and $95 \%$ confidence intervals (CI) of -17.8 to $-2.2 \%$ (adjusted odds ratio of $0.4 ; 95 \% \mathrm{CI}$ of $0.2-0.9 \%$ ). Thus, preoperative vaginal preparation using $1 \%$ povidone-iodine solution may decrease postoperative infectious morbidity. Compliance with the study's protocol (1,000 cc night before and day of surgery) may not be feasible in clinical practice (recommendation $\mathrm{C}$; level of certainty, moderate).

Skin incision types for abdominal hysterectomy have not been studied separately in a trial. The skin incision can be longitudinal or transverse. Many gynecologists choose a Pfannenstiel incision for its cosmetic appeal, which is a low transverse incision (recommendation I; level of certainty, low).

Skin incision length during abdominal hysterectomy can be $<6 \mathrm{~cm}$ (minilaparotomy) vs. $>6 \mathrm{~cm}$ (laparotomy). There have been no RCT trials comparing the minilaparotomy vs. laparotomy with transverse or longitudinal skin incision. There is one observational study [32] with 199 patients, comparing the outcome in $\leq 6 \mathrm{vs}>6 \mathrm{~cm}$ transverse incision. The investigators conclude that minilaparotomy is an option during $\mathrm{AH}$ for benign indications. The study was hampered not only by a nonrandomized design but also by having significantly different uterine sizes in the two groups. Thus, while minilaparotomy may be the clinicians' and patient's preference in certain clinical situations, it cannot be recommended to improve perioperative outcomes (recommendation, I; certainty low) 
Subcutaneous incision can be made either by a scalpel or electrocautery. One randomized clinical trial [16] with 380 patients was identified which compared electrocautery vs. scalpel in a subcutaneous incision during abdominal hysterectomy. Postoperative wound complications like seroma, hematoma, infection, or dehiscence were not significantly different in the two groups $(P=0.4)$. Thus, the subcutaneous tissue can safely be incised by either electrocautery or scalpel (recommendation, C; certainty, moderate).

Fascial incision has not been studied separately in a trial. In a low transverse Pfannenstiel incision, the fascia is usually incised transversely with the scalpel and then extended with scissors. Some clinicians advocate the use of electrocautery in the cutting mode for the fascial incision [33]. We did not identify any study ascertaining the optimum method to incise the fascia during $\mathrm{AH}$ (recommendations, I; certainty, poor).

Rectus fascia dissection of the rectus muscles with transverse fascial incision has not been studied separately during AH (recommendations, I; certainty, poor).

Opening of the peritoneum is achieved with either blunt or sharp dissection. During this surgical step, injury to the underlying organs and bladder inferiorly should be avoided. RCTs have not addressed what is the optimum manner to avoid these potential complications (recommendations, I; certainty, poor).

Retractors are used to improve the exposure during the surgery. The options include self-retaining (Balfour, Kerschner, Bookwalter, Omni-Tract, O'Conner-O'Sullivan, Mobius) or hand-held retractors (Heaney, Deaver, or Richardson). A potential complication with retractor usage is femoral nerve injury [34]. We were unable to identify any study that showed a significant decrease in the rate of this complication. Thus, the selection of the retractor should be based on surgeon's preference (recommendations, I; certainty, poor).

Ureter identification during $\mathrm{AH}$ is advocated to avoid injury that tends to occur at the infundibulopelvic ligament where the ovarian vessels are ligated, area of the uterine artery ligation, and the bladder base. The identification may be done by direct visualization of the ureter in the retroperitoneal space on the medial leaf of the broad ligament, palpation, or prophylactic placement of ureteral catheterization. No RCT has addressed the effect and/or optimum method of identification of the ureter to reduce its injury during $\mathrm{AH}$ alone (recommendations, I; certainty, low).

Vascular pedicles (involving, uteroovarian/infundibulopelvic ligaments, uterine vessels, and cardinal and uterosacral ligament) can be ligated by suture ligature, staples, or by electrocoagulation. Though an RCT [35] compared staples with suture ligature, we excluded this trial because the investigators did not mention if they used the stapling device for all vascular pedicles, and they used the stapling technique for the closure of vaginal vault. Thus, it is difficult to discern what aspect of surgical technique improved the operative outcome.

We identified two RCTs $(n=87)$ comparing suture ligature vs. bipolar vessel sealing device (LigaSure, Boulder CO) [17, 18]. Compared to suture ligature, use of bipolar vessel sealing device (LigaSure) for vascular pedicles significantly decreased $(P<0.01)$ the postoperative pain during the first three postoperative days [17]. There was no significant reduction in the operating time, blood loss, perioperative complications, and hospital stay [17, 18]. Thus, we recommend use of bipolar vessel sealing device (LigaSure) for vascular pedicles (recommendations, B; certainty, moderate).

Total vs. supracervical hysterectomy involves removal of the uterine body and the cervix in the former, while in the latter, the cervix is kept intact. A Cochrane review [36] summarized three RCT $(n=733)(-19,-21)$ comparing the perioperative outcomes with these two options. The length of surgery (weighted mean difference [WMD] of $11.4 \mathrm{~min}$, $95 \%$ CI 6.6-16.3 min), the estimated blood loss (WMD $85 \mathrm{ml} ; 95 \%$ CI $27-142 \mathrm{ml}$ ), and febrile morbidity (odds ratio [OR] 4.3; $95 \%$ CI $0.25-0.75$ ) were significantly reduced with supracervical hysterectomy. There was, however, no significant difference in the odds of requiring blood transfusion, duration of hospitalization, and return to normal activity. With supracervical hysterectomy, the likelihood of cyclical vaginal bleeding after 1 year was significantly higher when compared to total hysterectomy (11.9 vs. $0.8 \%$; OR 11.3, $95 \%$ CI 4.1, 31.2). At 2 years, however, there was no significant difference in ongoing bleeding. With 2 years after the surgery, there is no difference in the rate of urinary incontinence, constipation, and measures of sexual function.

One of the RCTs [22] summarized in the Cochrane review published follow-up (mean 9 years, range 7-11 years) of $65 \%$ (181 of 265) of the cohorts that were randomized. There was no long-term difference with total or supracervical hysterectomy with regards to quality of life, mental health, and pelvic organ function. Urinary and bowel function variables did not change significantly.

Thus, for short-term benefit (operative time, blood loss, and febrile morbidity), there is a role for supracervical abdominal hysterectomy in selected women, though there are no long-term advantages (recommendations, $\mathrm{C}$; certainty, high).

Vaginal cuff open vs. closed are the two options once the corpus and the cervix are removed. An open vaginal cuff may provide drainage and potentially prevents infective morbidity. We identified four RCTs $(n=612)$ published between 1992 and1998 [23-26]. Though they differed in how they closed the cuff and the primary outcomes, two of three RCTs noted a significant decrease in the operative time when the cuff was closed, possibly due to the hemostasis at the vaginal cuff obtained during closure with staples or sutures $[23,26]$. Using staples to close the cuff [23], there 
was significant improvement in intraoperative hemostasis and granulation at 6 weeks postoperative. Compared to when the cuff is open, the amount of fluid in the pelvis with a closed cuff is significantly higher on postoperative day 5 [26]. This, however, was not associated with improved febrile morbidity (recommendations, C; certainty, moderate).

Vaginal cuff closure may be achieved with absorbable staples or with sutures. Only one RCT $(n=60)$ compared these two options and noted that there was no significant difference in the operative time and febrile morbidity [27]. Thus, there is no clinical advantage of using staples (recommendations, $\mathrm{C}$; certainty, moderate).

Angle stitch consists of reattachment of cardinal and uterosacral ligament to the vaginal cuff with the aim of preventing apical prolapse [37]. Though classical teaching advocates this surgical step, we did not identify either RCT or observational studies (recommendations, I; certainty, low).

Intraabdominal irrigation, done to decrease perioperative morbidity with normal saline before abdominal wall closure, is advised [7]. We did not find any RCTs evaluating irrigation vs. no irrigation (recommendations, I; certainty, low).

Peritoneal closure involves closure of the parietal and visceral peritoneum. We identified three RCTs $(n=298)$ comparing closure of the peritoneum with nonclosure in AH. While two trials evaluated either visceral [28] or parietal peritoneal closure [29], one studied the closure of both layers [30]. Nonclosure of the peritoneum, when compared with closure of either single layer or both layers, significantly reduced the operative time in all three trials. The estimated blood loss is also significantly less in the nonclosure group in one trial $(45-\mathrm{ml}$ reduction, $P=0.03)$. There is no significant difference in the postoperative pain, febrile morbidity, wound infection, and hospital stay between peritoneal closure and nonclosure groups. Thus, routine peritoneal closure is not recommended (recommendations, D; certainty, moderate).

Techniques of fascial closure include use of running or interrupted delayed absorbable sutures. We did not identify any RCT studying facial closure technique in AH for benign pathology (recommendations, I; certainty, low).

Irrigation of the subcutaneous tissue to decrease wound complications in $\mathrm{AH}$ has not been evaluated separately by RCT (recommendations, I; certainty, low).

Subcutaneous tissue closure vs. no closure are two options before skin approximation to minimize woundrelated morbidity. We identified one RCT $(n=60)$ comparing closure with 2-0 polyglycolic acid (Dexon) vs. nonclosure in patients undergoing $\mathrm{AH}$ with $\geq 2.5-\mathrm{cm}$ thickness of the subcutaneous tissue [31]. Mid-line vertical incision was used in $47 \%$, while the remaining patients had a Pfannenstiel incision. There were fewer seromas, infections, and wound disruptions in the suture group, but statistical significance was not reached. The RCT lacked sample size calculations and did not perform any statistical analysis (recommendations, C; certainty, low).

Closure of the skin techniques include use of staples, subcuticular suture reinforced with surgical tape (e.g., Steri-Strips), or 2-octyl-cyanoacrylate skin adhesive (Dermabond, distributed by Ethicon, Inc). We did not find any RCTs that address the optimum method of skin closure in AH (recommendations, I; certainty, low).

\section{Comments}

In the USA [3], there are 69 hysterectomies performed per hour, and for benign disease, 41 abdominal hysterectomies are done every hour. While the likelihood of postoperative morbidity is about $4 \%$ [4], this rate may decrease further if RCTs with AH demonstrate a clinically significant decline in perioperative complications. A summary of published RCTs would not only allow us to identify the surgical steps that should be performed because of the existing evidence but also encourage investigators to design additional randomized studies.

There are three findings of this review. First, after reviewing over 3,000 abstracts, we identified only 19 RCTs [13-31] that met the inclusion criteria. These trials included 4,129 patients (Table 3 ). The surgical step with the largest number of cohorts $(n=1,899)$ examined the use of vaginal irrigation before $\mathrm{AH}$, and the one with the fewest patients ( $n=60)$ focused on closing the vaginal cuff with sutures vs. staples [33]. Interestingly, of these 19 studies, only three $[16,20,27]$ or $16 \%$ of RCTs were done in the USA. Thus, our evidence-based knowledge of $\mathrm{AH}$ is derived from a limited number of studies, with small sample size, done in foreign countries. There is, therefore, an urgent need for additional randomized trials, including in the USA.

The second finding is that $71 \%(15 / 21)$ of the surgical decisions gynecologists make during $\mathrm{AH}$ have insufficient (grade I) evidence. This is understandable considering the limited number of RCTs. About $24 \%$ (5/21) of surgical steps are based on grade $\mathrm{C}$ evidence, indicating that these steps should not be done routinely but on an individual basis. We identified only one $(5 \%)$ grade $\mathrm{D}$ recommendations and that is the peritoneum should not be closed. Using similar analysis, Berghella et al. [9] concluded that with cesarean delivery, neither parietal nor visceral peritoneal layer should be closed (grade D). Though there were no grade $\mathrm{A}$ recommendations for $\mathrm{AH}$, there was one grade $\mathrm{B}$ suggestion: compared to suture ligature, use of a bipolar vessel sealing device (LigaSure) for vascular pedicles significantly decreases postoperative pain during the first three postoperative days (Table 3 ). However, this study involved a small sample size of only 57 patients. Thus, if this surgical step is advocated to be done routinely, then an RCT that is compliant with Consolidated Standards of Reporting Trials (CONSORT) guidelines [38] should be conducted. 
Table 3 Evidence-based recommendations for abdominal hysterectomy

\begin{tabular}{|c|c|c|c|c|c|}
\hline Technical aspect & $\mathrm{RCT}$ & Number & $\operatorname{Rec}$ & Certainty & Comment \\
\hline Patient position & 0 & & I & Low & \\
\hline Skin cleaning & 0 & & I & Low & \\
\hline Vaginal preparation & 3 & 1,899 & $\mathrm{C}$ & Mod & $\begin{array}{l}\text { Povidone-iodine vaginal antisepsis may reduce } \\
\text { the overall infection morbidity after abdominal } \\
\text { hysterectomy. Compliance with protocol } \\
\text { (1,000 cc night before and day of surgery) } \\
\text { may not be feasible. }\end{array}$ \\
\hline Skin incision type & & & I & Low & \\
\hline Skin incision length (minilaparotomy) & 0 & & I & Low & \\
\hline Subcutaneous incision & 1 & 380 & $\mathrm{C}$ & Mod & $\begin{array}{l}\text { Incision of subcutaneous tissue by electrocautery } \\
\text { or scalpel does not influence the rate of wound } \\
\text { complications. }\end{array}$ \\
\hline Fascial incision & 0 & & I & Low & \\
\hline Rectus fascia dissection & 0 & & I & Low & \\
\hline Opening peritoneum & 0 & & I & Low & \\
\hline Retractors & 0 & & I & Low & \\
\hline Ureter identification & 0 & & I & Low & \\
\hline $\begin{array}{l}\text { Vascular pedicles: suture ligature vs. bipolar } \\
\text { vessel sealing device ligature }\end{array}$ & 2 & 87 & $\mathrm{~B}$ & Mod & $\begin{array}{l}\text { Compared to suture ligature, use of bipolar vessel } \\
\text { sealing device (LigaSure) for vascular pedicles } \\
\text { significantly decreases postoperative pain during } \\
\text { first } 3 \text { postoperative days. }\end{array}$ \\
\hline Total vs. supracervical hysterectomy & 4 & 733 & $\mathrm{C}$ & High & $\begin{array}{l}\text { Compared to total, supracervical hysterectomy is } \\
\text { associated with a significant decrease in the } \\
\text { duration } \\
\text { of surgery, intraoperative blood loss and fever. } \\
\text { Postoperative cyclical bleeding up to a year is } \\
\text { significantly more common with supracervical t } \\
\text { han total hysterectomy. }\end{array}$ \\
\hline Vaginal cuff open vs. closed (sutures or staples) & 4 & 612 & $\mathrm{C}$ & Mod & $\begin{array}{l}\text { With staples intraoperative time is significantly } \\
\text { reduced. Granulation at } 6 \text { weeks is significantly } \\
\text { less with staples than open. }\end{array}$ \\
\hline Vaginal cuff closed suture vs. staples & 1 & 60 & $\mathrm{C}$ & Mod & $\begin{array}{l}\text { No clinical advantage of closing the vaginal cuff } \\
\text { with suture or staple. }\end{array}$ \\
\hline Angle stitch & 0 & & I & Low & \\
\hline Intraabdominal Irrigation & 0 & & I & Low & \\
\hline Peritoneal closure & 3 & 298 & $\mathrm{D}$ & Mod & $\begin{array}{l}\text { Not recommended because peritoneal closure } \\
\text { provides no postoperative benefits while } \\
\text { unnecessarily increasing surgical time and } \\
\text { anesthesia exposure. }\end{array}$ \\
\hline Techniques of fascial closure & 0 & & $\mathrm{C}$ & Low & \\
\hline $\begin{array}{l}\text { Subcutaneous tissue closure } \\
\text { vs. nonclosure }\end{array}$ & 1 & 60 & I & Low & $\begin{array}{l}\text { No significant difference in closure vs no } \\
\text { closure but the trial design was poor. }\end{array}$ \\
\hline $\begin{array}{l}\text { Closure of skin with staples } \\
\text { vs. subcuticular suture }\end{array}$ & 0 & & I & Low & \\
\hline Total & $19^{\mathrm{a}}$ & 4,129 & & & \\
\hline
\end{tabular}

$R C T$ randomized clinical trial, $R e c$ recommendation

${ }^{\mathrm{a}}$ The Cochrane review [36] is a summary of three RCTs [19-21]

The third finding of the study focuses on the comparison of evidence for cesarean delivery (CD) vs. AH. The reasons for comparing the two surgeries are that they are the two most common major procedures done by an obstetriciangynecologist, and it allows us to determine to what extent
RCTs have been done to minimize postoperative morbidity. Previously, Berghella et al. [9] reported that, of 44 surgical decisions during $\mathrm{CD}, 16 \%$ had grade $\mathrm{A}$ recommendations compared to none for $\mathrm{AH}$. Overall, the distribution of the recommendations for the two common surgical procedures 
is significantly different $(P=0.029)$. For $\mathrm{CD}, 43 \%$ of the recommendations were grade I and for $\mathrm{AH}, 71 \%$. Thus, it seems more RCTs have been done for $\mathrm{CD}$ than $\mathrm{AH}$. Another difference noted between the different surgical steps of $\mathrm{CD}$ and $\mathrm{AH}$ is that, in $\mathrm{CD}$, the suture closure and drainage of $>2-\mathrm{cm}$ subcutaneous tissue has been recommended as level A $[9,39]$, whereas in $\mathrm{AH}$, the same recommendation was not observed. This may, again, be due to lack of adequately powered and designed trials.

There are several limitations of this study that should be acknowledged. We used the tenth edition of TeLinde's Operative Gynecology to ascertain the technique involved with $\mathrm{AH}$, and there may be surgical steps that were mentioned in earlier editions but are omitted in the latest. Edition $8[40,41]$ for example, described extra- vs. intrafascial $\mathrm{AH}$, and this is not described in the newest version. Though there is an RCT comparing extra- and intrafascial AH [42], we did not include this study in our summary because this step is not mentioned in the tenth edition. We acknowledge that though RCT may show clinical benefit, the recommendation may be difficult to implement in routine practice. Perioperative vaginal irrigation, for example, with $1,000 \mathrm{ml}$ of povidone-iodine vaginal antisepsis on the night before and prior to start of surgery decreased infectious morbidity [15] but seems difficult to implement routinely. While we excluded RCTs that combined AH with other major gynecological surgeries, there may be some useful information from these reports. We excluded manuscripts that focused on other surgeries in conjunction with $\mathrm{AH}$ and hysterectomy for cancer because the postoperative outcomes may be different when the surgery is done alone or without underlying cancer. Chou et al. [43] for example, randomized over 3,000 patients to either have or not have bilateral prophylactic ureteral catheter and reported that the likelihood of ureteral injury was similar. This conclusion may be valid with $\mathrm{AH}$ but needs confirmation. We did not determine if the RCT trials we included were compliant with the CONSORT statements or not [38]. Compliance with the statements improves the quality of the RCT, and noncompliance with them is associated with an overestimate of the effectiveness of intervention [44].

\section{Conclusion}

In summary, though abdominal hysterectomy is the most common major gynecologic surgery, there is a paucity of RCTs that minimize perioperative morbidity. Additionally, evidence with vaginal and laparoscopic hysterectomy needs to be reviewed.

Conflict of interest The authors report no conflicts of interest. The authors alone are responsible for the content and writing of the paper.

\section{References}

1. Whiteman MK, Hillis SD, Jamieson DJ, Morrow B, Podgornik $\mathrm{MN}$, Brett KM et al (2008) Inpatient hysterectomy surveillance in the United States, 2000-2004. Am J Obstet Gynecol 198:34.e134.e7

2. Keshavarz H, Hillis SD, Kieke BA, Marchbanks PA (2002) Hysterectomy surveillance-United States, 1994-1999. MMWR 51 (SS05): $1-8$

3. Wu JM, Wechter ME, Geller EJ, Nguyen TV, Cisco AG (2007) Hysterectomy rates in the United States, 2003. Obstet Gynecol 110:1091-1095

4. McPherson K, Metcalfe MA, Herbert A, Maresh M, Casbard A, Hargreaves J et al (2004) Severe complications of hysterectomy: the VALUE study. BJOG 111:688-694

5. Maresh MJ, Metcalfe MS, McPherson K, Overton C, Hall V, Hargreaves $J$ et al (2002) The VALUE national hysterectomy study: description of the patient and their surgery. BJOG 109:302-312

6. Kafy S, Huang JY, Al-Sunaidi M, Wiener D, Tulandi T (2006) Audit of morbidity and mortality rates of 1792 hysterectomies. J Minim Invasive Gynecol 13:55-59

7. Jones HW. Abdominal Hysterectomy. In Rock AJ, Jones HW (eds) Te Linde's Operative Gynecology, 10th edn. Lippincott Williams \& Wilkins, Philadelphia, pp 728-743

8. US Preventive Services Task Force. Agency for health care research and quality. www.ahcpr.gov/clinic/ajpmsuppl/harris3.htm. Last accessed July 12, 2009

9. Berghella V, Baxter JK, Chauhan SP (2005) Evidence-based surgery for cesarean delivery. Am J Obstet Gynecol 193(5):1607-1617

10. American College of Obstetricians and Gynecologists. Elective and risk-reducing salpingo-ophorectomy. ACOG practice bulletin No.89 Jan. 2008

11. American College of Obstetricians and Gynecologists. Antibiotic prophylaxis for gynecologic procedures. ACOG practice bulletin No.104 May 2009

12. American College of Obstetricians and Gynecologists. Prevention of deep venous thrombosis and pulmonary embolism. ACOG practice bulletin No. 84 August 2007

13. Vinkomin V (1995) Vaginal scrub prophylaxis in abdominal hysterectomy. Southeast Asian J Trop Med Pub Health 26:188-192

14. Eason E, Wells G, Garber G, Hemmings R, Luskey G, Gillett P, Martin M (2004) Vaginal Antisepsis For Abdominal Hysterectomy Study Group Antisepsis for abdominal hysterectomy: a randomised controlled trial of povidone-iodine gel. BJOG 111:695-699

15. Buppasiri P, Chongsomchai C, Wongproamas N, Ounchai J, Suwannachat B, Lumbiganon P (2004) Effectiveness of vaginal douching on febrile and infectious morbidities after total abdominal hysterectomy: a multicenter randomized controlled trial. J Med Assoc Thai 87:16-23

16. Hemsell DL, Hemsell PG, Nobles B, Johnson ER, Little BB, Heard M (1993) Abdominal wound problems after hysterectomy with electrocautery vs. scalpel subcutaneous incision. Infect Dis Obstet Gynecol 1:27-31

17. Lakeman M, Kruitwagen RF, Vos MC, Roovers JP (2008) Electrosurgical bipolar vessel sealing versus conventional clamping and suturing for total abdominal hysterectomy: a randomized trial. J Minim Invasive Gynecol 15:547-553

18. Hagen B, Erikson N, Sundset M (2005) Randomized controlled trial of LigaSure versus conventional suture ligature for abdominal hysterectomy. BJOG 112:968-970

19. Gimbel H, Zobbe V, Andersen BM, Filtenborg T, Gluud C (2003) Tabor A randomised controlled trial of total compared with subtotal hysterectomy with one-year follow up results. BJOG 110(12):10881098 
20. Learman LA, Summitt RL Jr, Varner RE, McNeeley SG, Goodman-Gruen D, Richter HE, Lin F, Showstack J, Ireland CC, Vittinghoff E, Hulley SB, Washington AE (2003) A randomized comparison of total or supracervical hysterectomy: surgical complications and clinical outcomes. Total or Supracervical Hysterectomy (TOSH) Research Group. Obstet Gynecol 102(3):453-462

21. Thakar R, Ayers S, Thakar R, Ayers S, Gerogakapolou, Clarkson P, Stanton S, Manyonda I (2004) Hysterectomy improves quality of life and decreases psychiatric symptoms: a prospective and randomized comparison of total versus subtotal hysterectomy. BJOG 111:1115-1120

22. Thakar R, Ayers S, Srivastava R, Manyonda I (2008) Removing the cervix at hysterectomy: an unnecessary intervention? Obstet Gynecol 112:1262-1269

23. Kalbfleish RE (1992) Prospective randomized study to compare a closed vault technique using absorbable staples at the time of abdominal hysterectomy versus open vault technique. Surg Gynecol Obstet 175:337-340

24. Neuman M, Beller U, Ben Chetrit A, Lavie O, Boldes R, Diamant $Y$ (1993) Prophylactic effect of the open vaginal vault method in reducing febrile morbidity in abdominal hysterectomy. Surg Gynecol Obstet 176:591-593

25. Colombo M, Maggioni A, Zanini A, Rangoni G, Scalambrino S, Mangioni C (1995) A randomized trial of open versus closed vaginal vault in the prevention of postoperative morbidity after abdominal hysterectomy. Am J Obstet Gynecol 173:1807-1811

26. Aharoni A, Kaner E, Levitan Z, Condrea A, Degani S, Ohel G (1998) Prospective randomized comparison between an open and closed vaginal cuff in abdominal hysterectomy. Int $\mathrm{J}$ Gynaecol Obstet 63:29-32

27. Stovall TG, Summitt RL Jr, Lipscomb GH, Ling FW (1991) Vaginal cuff closure at abdominal hysterectomy: comparing sutures with absorbable staples. Obstet Gynecol 78:415-418

28. Kucuk M, Okman TK (2001) Non-closure of visceral peritoneum at abdominal hysterectomy. Int J Gynecol Obstet 75:317-319

29. Al-Inany H (2004) Peritoneal closure vs. non-closure: estimation of pelvic fluid by transvaginal ultrasonography after abdominal hysterectomy. Gynecol Obstet Invest 58:183-185

30. Gupta JK, Dinas K, Khan KS (1998) To peritonealize or not to peritonealize? A randomized trial at abdominal hysterectomy. Am J Obstet Gynecol 178:796-800

31. Kore S, Vyavaharkar M, Akolekar R, Toke A, Ambiye VJ (2000) Comparison of closure of subcutaneous tissue versus non-closure in relation to wound disruption after abdominal hysterectomy in obese patients. J Postgrad Med 46:26-28

32. Sharma J, Wadhwa L, Malhotra M, Arora R (2004) Mini laparotomy versus conventional laparotomy for abdominal hysterectomy: a comparative study. Indian J Med Sci 58:196-202

33. Kearns SR, Connolly EM, McNally S, McNamara DA, Deasy J (2001) Randomized clinical trial of diathermy versus scalpel incision in elective laparotomy. Br J Surg 8:41-44

34. Chan JK, Manetta A (2002) Prevention of femoral nerve injuries in gynecologic surgeries. Am J Obstet Gynecol 186:1-7

35. Beresford JM, Moher D (1993) A prospective comparison of abdominal hysterectomy using absorbable staples. Surg Gynecol Obstet 176:555-558

36. Lethaby A, Ivanova V, Johnson NP (2006) Total versus subtotal hysterectomy for benign gynaecological conditions. Cochrane Database Syst Rev 19(2):CD004993

37. Rahn DD, Stone RJ, Vu AK, White AB, Wai CY (2008) Abdominal hysterectomy with or without angle stitch: correlation with subsequent vaginal vault prolapse. Am J Obstet Gynecol 199:669.e1-669.e4

38. Begg CB, Cho M, Eastwood S, Horton R, Moher D, Olkin I et al (1996) Improving the quality of reporting of randomized controlled trials. The CONSORT statement. JAMA 276:637-639

39. Ramsey PS, White AM, Guinn DA, Lu GC, Ramin S, Davies JK et al (2005) Subcutaneous tissue reapproximation, alone or in combination with drain, in obese women undergoing cesarean delivery. Obstet Gynecol 105:967-973

40. Thompson JD, Warshaw, J. Hysterectomy. In Rock AJ, Thompson JD (eds) Te Linde's Operative Gynecology, Eighth edn. Lippincott-Raven, pp 771-85440

41. Kaya H, Sezik M, Ozbasar D, Ozkaya O, Sahiner H (2004) Intrafascial versus extrafascial abdominal hysterectomy: effects on urinary urge incontinence. Int Urogynecol J 15:171-174

42. Kaya H, Sezik M, Ozbasar D, Ozkaya O, Sahiner H (2004) Intrafascial versus extrafascial abdominal hysterectomy: effects on urinary urge incontinence. Int Urogynecol J 15:171-177

43. Chou MT, Wang CJ, Lien RC (2009) Prophylactic ureteral catheterization in gynecologic surgery: a 12-year randomized trial in a community hospital. Int Urogynecol J 20:689-693

44. Moher D, Jones A (2001) Lepage LCONSORT Group. (Consolidated Standards for Reporting of Trials). Use of the CONSORT statement and quality of reports of randomized trials: a comparative before-andafter evaluation. JAMA 285:1992-1995 